Article

\title{
Evaluating International Tourists' Perceptions on Cultural Distance and Recreation Demand
}

\author{
Chun-Hung Lee ${ }^{1}$, Han-Shen Chen ${ }^{2,3}$ (), Gwo-Bao Liou ${ }^{4}$, Bi-Kun Tsai ${ }^{5}$ and Chi-Ming Hsieh ${ }^{6, *}$ \\ 1 Department of Natural Resources and Environmental Studies, National Dong Hwa University, No. 1, Sec. 2, \\ Da Hsueh Rd, Hualien 97401, Taiwan; chlee@mail.ndhu.edu.tw \\ 2 Department of Health Diet and Industry Management, Chung Shan Medical University, No. 110, Sec. 1, \\ Jianguo N. Rd., Taichung City 40201, Taiwan; allen975@csmu.edu.tw \\ 3 Department of Medical Management, Chung Shan Medical University Hospital, No. 110, Sec. 1, \\ Jianguo N. Rd., Taichung City 40201, Taiwan \\ 4 School of Liberal Education, Shin Chien University Kaoshiung Campus, No. 200, University Rd., \\ Neiman Dist., Kaoshiung City 845, Taiwan; assure2012@gmail.com \\ 5 Graduate Institute of Bio-Industry Management, National Chung Hsing University, 145 Xingda Rd., \\ South Dist., Taichung City 40227, Taiwan; pktsai@dragon.nchu.edu.tw \\ 6 International Bachelor Program of Agribusiness, National Chung Hsing University, 145 Xingda Rd., \\ South Dist., Taichung City 40227, Taiwan \\ * Correspondence: hsiehch9@nchu.edu.tw; Tel.: +886-4-2284-0849 (ext. 622)
}

Received: 10 October 2018; Accepted: 13 November 2018; Published: 22 November 2018

\begin{abstract}
This study employed the travel cost method (TCM) to establish the on-site Poisson model to measure differences in the recreation benefits of Chinese inbound tourists based on the identified cultural distance clusters. Four clusters among the extracted factors of delineated perceptions on cultural distance were identified through the cluster analysis. This study finds that: (1) among four identified cognitive factors of the cultural distance, "social environment" and "personal relationship" were found to be more important than "living arrangement" and "verbal communication" factors; (2) the four cultural distance clusters differ significantly in terms of perceptions on the cultural distance; (3) the economic benefits of culture and heritage tourism ranged between US\$4733 to US\$6740 for average annual Chinese visitor numbers to Taiwan; (4) the "similar living habits" cluster had higher recreation benefits than the other three cultural distance clusters. The government and travel industries should pay attention to target segments in order to enhance the cultural heritage experience, by delivering an appropriate quality of service to match visitors' needs and living habits, which in turn, impacts their revisit intent.
\end{abstract}

Keywords: cultural distance; travel cost; recreational demand; inbound tourist

\section{Introduction}

According to the World Travel and Tourism Council [1], in 2017, travel and tourism's direct contribution to GDP of the world was US\$ 8.3 trillion. The total contribution of travel and tourism comprised $10.4 \%$ of GPD of the world, and generated over 313 million jobs. It has been forecasted that the total contribution from travel and tourism to the world economy would be $2.9 \%$, and that travel and tourism in North East Asia leads the world with estimated growth of 7.4\% in 2017 [2]. In Taiwan, the total contribution of the travel and tourism industry to GDP was US\$ 24.4 billion, an estimate of $4.3 \%$ of GDP in 2017 [2]. In particular, leisure travel spending of inbound and domestic tourists generated $81.7 \%$ of direct travel and tourism GDP in 2017 and is expected to grow by $3.6 \%$ in 2018 . The total number of inbound tourists to Taiwan was approximately 10.74 million in 2017, and the majority of inbound tourists (89.3\%) to Taiwan arrived primarily from Asian countries [3]. Table 1 
presents the number and percent of the top 10 international visitor arrivals to Taiwan by residence in 2017 [4]. With the continuously growing contribution of tourism industry to national and world economies, it is crucial to understand the decision-making process of international tourists in selecting a travel destination and activities. Particularly, national culture's similarities or differences between a home country and a traveling country plays a crucial role in understanding travel demand.

Table 1. Number and percentage of top 10 international visitor arrivals to Taiwan by residence in 2017.

\begin{tabular}{cccc}
\hline Rank & Country of Residence & Number of Visitors & Percent (\%) \\
\hline 1 & Mainland China & $2,732,549$ & 28.3 \\
\hline 2 & Japan & $1,898,854$ & 19.6 \\
\hline 3 & Hong Kong + Macao & $1,692,063$ & 17.5 \\
\hline 4 & Korea & $1,054,708$ & 10.9 \\
\hline 5 & U.S.A. & 561,365 & 5.8 \\
\hline 6 & Malaysia & 528,019 & 5.4 \\
\hline 7 & Singapore & 425,577 & 4.4 \\
\hline 9 & Thailand & 292,534 & 3.1 \\
\hline 10 & Philippines & 290,784 & 3.0 \\
\hline & Indonesia & 189,631 & 2.0 \\
\hline
\end{tabular}

Source: Tourism Bureau Ministry of Taiwan (2018) [3].

Culture is the integrated traits of learned behavior, which are commonly shared and transmitted by the members of a particular society [5]. Cultural values of a country differ from those of another country, even though these countries are possessing similar ethnicity and background [6-8]. Much research shows that people from different countries and cultures have different travel needs, preferences, patterns and activities [9-17]. Specifically, selecting a travel destination is directly associated with cultural attributes [18-21]. Cultural similarities or differences are a strong influence on tourists' choices. Cultural distance is an important concept of assessing behavioral gaps of international tourists that shows the degree of cultural differences between the similarities and differences from tourist's home to destination countries [6,18,22]). According to Clark and Pugh (2001, p. 296) [6], cultural distance is defined as "the degree of difference of the cultural cluster to which the target foreign country belongs from the cultural cluster to which the home country belongs." Previous studies demonstrated that cultural distance has impacts on international destination choices and travel decisions [18,23-25] as well as being used as a tool to measure cultural similarities and differences between countries [22,26,27]. However, cultural differences often occurred regardless of national boundaries according to their languages, ethnic, or religious divides. Moreover, Gómez Parra (2009) [28] claimed the concept of cultural distance exists between persons speaking the same language, but who do not share the same cultural values. Based on the study of Hofstede (2001) [29], Asian societies have higher values in power distance, collectivism and maintain a long-term orientation as well as showing mixed values of masculinity and uncertainty avoidance characteristics. In addition, the Confucianism is the foundation of the Chinese traditional culture shared with the Great Chinese Regions such as Mainland China, Taiwan, Hong Kong, and Macau. However, these regions are also represented by their own cultural characteristics which attract different types of tourists based on their geographical, historical, political, and economic conditions. Understanding international tourists' perception of cultural distance from their home to host cultures allows researchers and marketers to better define the value of tourism behavior and future travel patterns. The paper is structured in five parts. The authors introduce the general scope of the paper in the beginning. Section 2 reviews the literature on the Cultural Distance Theory and the analysis of travel demand. Section 3 describes research methodology, including data 
collection, measurement and the travel demand estimation. The paper's results and discussion are presented in Section 4. Section 5 consists of conclusions based on the empirical results, management implications, and limitations and suggestions for future research.

The purpose of this study is to analyze the factors of perceptions of cultural distance, and to estimate the travel demands for Mainland China, Hong Kong, and Macau tourists who travel in Taiwan based on their perception of cultural distances using by travel cost method (TCM). The specific objectives are: (1) to identify underlying dimensions of perceived cultural distance; (2) to segment international tourists based on their perceived cultural distance; and (3) to estimate recreational benefits of each cluster, including evaluations of price elasticity, cross elasticity, and income elasticity. This paper may contribute to the literature by evaluating inbound tourists' perceptions on cultural distance to investigate the recreational benefits. The findings could bridge the gap on the impact of perceived cultural similarity on the visiting intentions for a foreign destination.

\section{Literature Review}

\subsection{Cultural Distance Theory}

Cultural distance refers to the extent to which the culture of the originating place differs from that of the host place [30]. Cultural distance is often used to measure national level differences between countries (e.g., Clark and Pugh, 2001 [6]; Shenkar, 2001 [22]). People from more culturally distant places are more or less motivated to travel across the border remains inconclusive. Previous studies have shown that residents' attitudes towards tourists and tourists' behaviors at a destination are directly influenced by the types of contacts and interactions taking place between the two groups as well as the emotional solidarity and social distance between the groups [31-33]. Nyaupane et al. [34] point out that social distance determined the relational structures, similarities and dissimilarities between travelers of different faiths consuming the same tourism spaces. Social distance has been used considerably less in the field of tourism studies, with only a few exceptions [32,35] that primarily examine the relationships between the outside visitors and the people being visited.

$\mathrm{Ng}$ et al. [18] revealed that there is a negative relationship between cultural distance and intention to travel for Australians. Specifically, the greater the perceived cultural similarity of a foreign destination to the home country, the more likely tourists would visit the destination [18]. On the contrary, McKercher and Chow [36] found that tourists to Hong Kong from culturally proximate countries were less interested in cultural tourism, whereas tourists from culturally distant places were more likely to feel that Hong Kong is rich in culture, history, and heritage. Jackson [23] showed that people from high individualist countries such as United States were more likely to choose culturally similar destinations, while people from high collectivistic countries such as South Korea tended to choose culturally dissimilar destinations. With these mixed results, and the continued international tourism market, particularly in Taiwan, it is critical for incorporating cultural distance as a key variable in understanding tourist destination choice and tourist demand. Proquest had retrieved 25 studies that measured cultural distance [18], and found that 19 studies adopted Kogut and Singh's [37] index to measure power distance, uncertainty avoidance, collectivism and women specialty manhood individualism based on Hofstede [38]. Four studies used a self-evaluation measurement scale (the cultural value of cognition grade). Interviewees were requested to evaluate the cultural distance between their own country and the destination country. Two studies used Clark and Pugh's [6] cluster analysis method, which is based on Ronen and Shenkar's [39] national map. Other previous research has measured cultural distance based on language foundation [40]. Jackson's [23] indicators of cultural difference summarized Hofstede's [38] four dimensions to evaluate the degree of cultural distance. $\mathrm{Ng}$ et al. [18] adopted five indicators to measure cultural distance. This study employs the cultural value method of cognition to measure the cultural distance of Chinese inbound tourists to Taiwan by employing Clark and Pugh's [6] cluster method, West and Graham's [40] language distance, and Spradley and Philips' [41] culture and concept of pressure design. After measuring difference intensity of cultural and cognitive distance of Chinese inbound tourists to Taiwan before and after 
traveling, it is then incorporated into the travel demand model. The following section discusses the travel demands of Chinese inbound tourists to Taiwan.

\subsection{Travel Demand of Inbound Tourists}

Hotelling [42] first proposed the traveling cost method (TCM), and observed the travel distance and participation rate in various residential areas to derive the demand function used to determine recreational benefit. In 1966, Clawson and Knetsch [43] expanded the TCM into the so-called traditional evaluation method of travel cost, and applied it to the assessment of recreational value of national parks in the United States [44]. Lee's [45] study of travel demand in Taiwan utilized the on-site Poisson model to estimate the travel demand of the Yilan Green Expo in 2006 year to examine differences in travel demand, various elasticity, and recreational benefits in festival participants with various motivations. Lee and Huang's [46] study adopted the Panel Poisson demand model to analyze the travel demand for festival activities, as well as the elasticity of demand, cross-elasticity, and income elasticity to test the structural change of the travel demand caused by the reduction of the crowded consciousness. This study identifies the similarities and differences of various cultures that could affect the travel choices of tourists. Lee and Chen's [47] study used the maximum likelihood estimation to evaluate the demand model of festival activities, including the elasticity of demand, cross-elasticity, and income elasticity of the Yilan Green Expo in 2007. There are various travel demands of Chinese inbound tourists to Taiwan from different cultures, such as travel pattern [12-14,48] and preferred tourism activity [15-17]. Recent studies have focused on hospitality, attitude, and behavioral intention [49]; travel motivation, perceived value, satisfaction, and loyalty [50]; travel purchase behavior and decision making [51]; travel behavior, satisfaction, and revisit intention [52]; travel image in Taiwan [53]; and the impacts of the socioeconomic background and travel characteristic on travel satisfaction [54]. This study identifies the similarities and differences of various cultures that could affect the travel choices of tourists. No study has identified or considered cultural distance as a factor of travel demand. Thus, this study employs the concept of cultural distance to evaluate Chinese inbound tourists to Taiwan, and further combines the cognitive clusters to assess the differences of price elasticity and income elasticity among clusters to reduce the gap in the literature.

\section{Methods}

\subsection{Instrument Development and Measurement Scales}

A review of the extant literature regarding inbound tourist experiences provides the foundation for the development of item statements in the questionnaire, containing rating-scale questions. This study reviews extant research relevant to cultural distance dimensions $[6,18,39,40,55]$. The measurement items of assessing perceptions of cultural distance were primarily adopted from Clark and Pugh's [6] cultural cluster distance index, West and Graham's [40] language distance, and Spradley and Philips' [4] Cultural Readjustment Rating Questionnaire (CRRQ) in terms of lifestyle, languages, relationship and mutuality. Finally, a self-administered survey with the use of close-ended questions was designed to obtain information about participants' perceptions of cultural distance, demographic information, and travel behavior of staying in Taiwan. Specifically, the questionnaire was comprised of 20 items for measuring cultural and cognitive distance, seven items of demographic variables, and nine items of travel behavior of the international Chinese tourists visiting Taiwan. A five-point Likert scale was used, with a range of 1 (strongly disagree) to 5 (strongly agree). A purposive sampling method of non-random sampling was employed to collect data among selected Chinese tourists traveling in Taiwan. According to statistics [4], three most famous tourist destinations attracted by international inbound tourists in Taiwan were the National Palace Museum, Taroko National Park, and Taipei 101. Three destinations all provide the features of culture, heritage, tradition, or nature in Taiwan. A pilot study with 50 samples was employed during one month to ensure that the measurement scales worked adequately, and to refine the data collection procedures, prior to collecting the data for the main study. Afterward, a formal study survey was administered in above three places, and the data were 
collected from Mainland Chinese, Hong Kong and Macau tourists around six months. Exploratory factor analysis and cluster analysis were employed to identify underlying dimensions of cultural distances and different clusters with various Cronbach's Alpha was calculated as reliability parameter to indicate the internal consistency of the items with each dimension.

\subsection{Travel Cost Method}

This study employs the Travel Cost Method (TCM) to establish the travel demand model for international inbound tourists from Mainland China, Hong Kong and Macau to Taiwan. To understand the travel behavior and demand, as well as the cultural and cognitive distance of Chinese inbound tourists, this study uses the TCM model to estimate the recreational benefit of international Chinese tourists to Taiwan. The TCM model is suitable for further evaluating the travel demand based on the four factorial and cognitive clusters extracted from the factor and cluster analyses. The on-site Poisson model was adopted to estimate the recreation demand function, and to further evaluate the price and income elasticity of the differences in travel behavior. Hence, this study employed the Marshallian demand function to measure the consumer surplus (CS) among targeted clusters. Namely, the elasticity estimation was used to assess the differences of the recreational benefits through the perceived quality improvement among Chinese tourists to Taiwan. To identify cognitive and cultural factors, this study employs a questionnaire survey which includes items that measure travel experiences (e.g., travel expenditure, length of stay, flight time between two countries), socioeconomic background (e.g., gender, income), and further explains the consideration with selection of variables in the estimation of TCM model.

\section{Results and Discussion}

\subsection{Sample Profile}

A total of 749 effective samples were collected with the response rate of $90.3 \%$. Of the respondents, $50.9 \%$ were male and $50.3 \%$ were single. The majority of respondents were from Mainland China $(59.3 \%)$, Hong Kong $(29.4 \%)$, and Macau (11.3\%). The majority ranged in age from 20 to $29(29.3 \%)$ and from 30 to $39(25.1 \%)$. Slightly less than half $(46.3 \%)$ worked in service industries $(24.0 \%)$ and in the commerce sector (22.3\%). Monthly income was reported as less than US\$ 760 (44.1\%), followed by US\$761-US\$1670 (29.9\%).

\subsection{Factor Analysis of the Cultural Distance}

To identify underlying dimensions of the cultural distance, a principal component analysis was applied to condense the initial 20 items into smaller numbers. One item with cross-loadings was removed. The value of Bartlett's test and Kaiser-Meyer-Olkin (KMO) were 4444.89 and 0.934 respectively, showing that the data was suitable for factor analysis [56]. Four factors emerge with eigenvalues greater than one, accounting for $54.51 \%$ of the variance in the sample. The results of varimax rotation are shown in Table 2, where only factor loadings greater than 0.45 were presented [57]. According to the parameter factor load type attitude, this research details the factors extracted from the cultural and cognitive distance as follows:

Factor I: Social environment. This factor construct comprises seven items $(\alpha=0.80$, Eigenvalues $=3.12$, total explained variance $=16.41 \%$ ). The order of the value of factor loading is lignin-environment, the pace of life, cleaning habits, food type, lifestyle, mode of transportation, and religious beliefs. This construct is closely linked with local living environment which the travelers can experience directly; thus, this construct is named "social environment." Because this construct has the highest Eigenvalues and total explained variation, it becomes a critical factor for measuring the cultural and cognitive distance of Chinese inbound tourists to Taiwan.

Factor II: Personal relationship. This factor construct is comprised of five items $(\alpha=0.81$, Eigenvalues $=3.08$, total explained variance $=16.23 \%$ ). The value of factor loading in order is: the 
degree that people express friendliness and hospitality, interactive relationships, punctuality, courtesy, and historical backgrounds. This construct is closely linked with interpersonal relationships; thus, this construct is named "personal relationship." This construct has the second-highest Eigenvalues and total explained variance; therefore, it has a crucial role in measuring the cultural and cognitive distance of Chinese inbound tourists to Taiwan.

Factor III: Living arrangements. This factor construct comprises five items $(\alpha=0.74$, Eigenvalues $=2.40$, total explained variance $=12.64 \%$ ). The value of factor loading in order is: similar geographical distance, amusement type and recreation activity, attire, sleeping patterns, and diet. This construct is closely linked with the degree of geographical distance; therefore, it is named "living arrangements."

Factor IV: Verbal communication. This factor construct comprises two items with $(\alpha=0.67$, Eigenvalues $=1.76$, total explained variance $=9.22 \%$ ). The value of factor loading in order is: prevalence of language use, and the degree of similarity between languages used. This construct is closely linked with the language; therefore, it is named "verbal communication."

Table 2. Factor analysis of the cultural distance of the Chinese inbound tourist after travel.

\begin{tabular}{|c|c|c|c|c|}
\hline Cultural Distance Dimension & $\begin{array}{c}\text { Factor } \\
\text { Loading }\end{array}$ & $\begin{array}{l}\text { Eigen } \\
\text { Values }\end{array}$ & $\begin{array}{c}\text { Total } \\
\text { Explained } \\
\text { Variation (\%) }\end{array}$ & Cronbach's $\alpha$ \\
\hline Factor I: Social environment & & 3.12 & 16.41 & 0.80 \\
\hline living environment & 0.72 & & & \\
\hline the pace of life & 0.63 & & & \\
\hline cleaning habits & 0.60 & & & \\
\hline food type & 0.60 & & & \\
\hline lifestyle & 0.55 & & & \\
\hline transportation system & 0.51 & & & \\
\hline religious belief & 0.49 & & & \\
\hline Factor II: Personal relationship & & 3.08 & 16.23 & 0.81 \\
\hline the degree of people expresses friendly and intimacy & 0.73 & & & \\
\hline interactive relationship & 0.70 & & & \\
\hline on time concept & 0.65 & & & \\
\hline courtesy & 0.58 & & & \\
\hline historical backgrounds & 0.46 & & & \\
\hline Factor III: Living arrangements & & 2.40 & 12.64 & 0.74 \\
\hline similar geographical distance & 0.68 & & & \\
\hline amusement and recreation activity & 0.60 & & & \\
\hline way to dress & 0.58 & & & \\
\hline arrangement of sleeping time & 0.48 & & & \\
\hline arrangement of diet & 0.48 & & & \\
\hline Factor IV: Verbal communication & & 1.76 & 9.22 & 0.67 \\
\hline prevalence of the usage of the language & 0.79 & & & \\
\hline degree of similarity of the used language & 0.79 & & & \\
\hline Total explained variation (\%) & & & 54.51 & 0.90 \\
\hline
\end{tabular}

The discussed factor analysis results show that Chinese inbound tourists to Taiwan primarily possess the component of "social environment," followed by "personal relationship." Therefore, we can assert that Chinese inbound tourists to Taiwan focus primarily on local living environments that are 
similar to those in China. Byrne and Nelson [58] claimed that people are attracted to other countries that have similar attitudes and faith. Although this assumption is based in the social psychology domain, there is sufficient supporting evidence for its applicability in a commercial context. Political and economic factors produce images of a destination country, and the cultural, social, and environmental impacts of the destination country facilitate tourists' purchase intention of the local products. For example, Wang and Lamb [59] showed that Americans typically buy the products from countries with a democratic style of government. Watson and Wright [60] also showed that the consumers of with sense of superiority believe it is comparatively suitable to import products from countries with a similar culture. It is especially crucial in the tourism industry to prove that there is significant cultural difference between tourists' own countries and the destination country. For example, Spradley and Philips [41] claimed that diet, language, neat and tidy, pace of life, amusement, living standards, vehicle, sense of humor, intimacy, privacy, and courtesy require adjustment in order to help visitors clearly have goals such as recreational amusement or appreciation of special scenery. In other words, visiting destinations with similar culture could reduce the intensity of cultural and social impacts, thereby producing a positive experience [18]. Therefore, we can infer that similarities in the social environment between China and Taiwan could be of significant assistance to the Taiwanese tourism industry.

\subsection{Cluster Analysis of the Cultural Distance}

This study employs cluster analysis to identify different groups with various cultural distances to examine the differences in cultural and cognitive distance among the cluster groups. Using non-hierarchy K-means analysis [61], four-cluster classification was selected. The results indicated that the Clusters I, II, III, and IV comprise of 144 (19.23\%), $129(17.22 \%), 214(28.57 \%)$, and 262 people $(34.98 \%)$, respectively (Table 3$)$. After confirming the number of clusters, analysis of variance (ANOVA) was used to obtain the mean cultural distance value for the four clusters. Scheffe's test was then used to identify the difference between paired groups. Each cultural distance construct was named according to the characteristic of each factorial construct showed in Table 2. Based on the Scheffe's test results, except for Clusters I and II on Factor I (social environment) and Factor IV (verbal communication); Clusters I to III on Factor I (social environment); and Clusters I to IV on Factor IV (verbal communication), the remaining clusters on four factors are significantly relevant. Thus, the market of Chinese inbound tourists to Taiwan could be effectively segmented according to cultural and cognitive distances. Each cluster in the cultural market segmentation are detailed as follows:

Cluster I: Interactive communication. Cluster I is comprised of 144 people. Factor IV (verbal communication) has the highest degree of agreement (3.87), followed by Factor II (personal relationship) (3.69). Because Factor I (social environment) and factor II (personal relationship) are both within their own clusters, their scores are higher than Clusters II and III. Therefore, Cluster I is named "interactive communication."

Cluster II: Integrative heterogeneity. Cluster II is comprised of 129 people and is the smallest cluster in this study. Factor IV (verbal communication) has the second highest score among the four factors, although it is lower than that of Cluster III because of the average score (less than 3) of Factors I (social environment), II (personal relationship), and III (living arrangements). This shows that the Chinese inbound tourists perceive a greater difference between Taiwan and China. Thus, this Cluster II is named "integrative heterogeneity."

Cluster III: Similar living habits. Cluster III is comprised of 214 people. Factor III (living arrangements) has the highest degree of agreement (3.36) in terms of degree of the agreement, followed by Factor IV (verbal communication) (3.08). Cluster III is named "similar living habits" because Factor III (living arrangements) is within its own cluster and has the second-highest score among Clusters I, II, and III.

Cluster IV: Cultural similarity. Cluster IV comprises 262 people and has the highest score for all four factors among all clusters. This shows that Chinese inbound tourists perceive similarities between Taiwan and China. Thus, Cluster II is named "cultural similarity." 
Table 3. One-way ANOVA of cluster types extracting from the factor analysis of the cultural distance.

\begin{tabular}{|c|c|c|c|c|c|c|c|c|c|c|c|}
\hline \multirow{2}{*}{$\begin{array}{l}\text { Clusters } \\
\text { Factors }\end{array}$} & \multirow{2}{*}{$\begin{array}{c}\text { Interactive } \\
\text { Communication }(\mathrm{n}=144) \\
\text { I }\end{array}$} & \multirow{2}{*}{$\begin{array}{c}\text { Integrative } \\
\text { Heterogeneity }(\mathrm{n}=129) \\
\text { II }\end{array}$} & \multirow{2}{*}{$\begin{array}{c}\text { Similar Living Habits } \\
(\mathrm{n}=214) \\
\text { III }\end{array}$} & \multirow{2}{*}{$\begin{array}{c}\text { Cultural Similarity } \\
(\mathrm{n}=262) \\
\text { IV }\end{array}$} & \multirow{2}{*}{ F Value } & \multicolumn{6}{|c|}{ Scheffe Multiple Range Tests } \\
\hline & & & & & & I-II & I-III & I-IV & II-III & II-IV & III-IV \\
\hline $\begin{array}{l}\text { Factor I: } \\
\text { Social } \\
\text { environment }\end{array}$ & 2.72 & 2.67 & 2.81 & 3.82 & 300 & $\mathrm{n} / \mathrm{a}$ & $\mathrm{n} / \mathrm{a}$ & $* * *$ & * & $* * *$ & $* * *$ \\
\hline $\begin{array}{l}\text { Factor II: } \\
\text { Personal } \\
\text { relationship }\end{array}$ & 3.69 & 2.65 & 2.83 & 3.86 & 216 & $* * *$ & $* * *$ & $* *$ & $* *$ & $* * *$ & $* * *$ \\
\hline $\begin{array}{l}\text { Factor III: } \\
\text { Living } \\
\text { arrangements }\end{array}$ & 3.54 & 2.55 & 3.36 & 3.82 & 128 & $* * *$ & $* *$ & $* * *$ & $* * *$ & $* * *$ & $* * *$ \\
\hline $\begin{array}{l}\text { Factor IV: } \\
\text { Verbal } \\
\text { communication }\end{array}$ & 3.87 & 3.71 & 3.08 & 3.99 & 43 & $\mathrm{n} / \mathrm{a}$ & $* * *$ & $\mathrm{n} / \mathrm{a}$ & $* * *$ & $* *$ & $* * *$ \\
\hline
\end{tabular}

Note: $\mathrm{n} / \mathrm{a}$ is non-significant; ${ }^{* * *}$ at the significant level of $1 \%$; ** at the significant level of $5 \%{ }^{*}$ at the significant level of $10 \%$; The mean of the factor analysis of cultural distance is based on the degree of similarity of the subjects' responses with five Likert scale ranging from 1 (very similar) to 5 (very unsimilar). 
Based on this analysis, this study divides Chinese inbound tourists to Taiwan into the following four clusters: social environment; personal relationship; living arrangements, and verbal communication. Cluster IV accounts for $34.98 \%$ of all participants and is the largest cluster. Conversely, Cluster I (interactive communication) only accounts for $17.22 \%$ of the participants and is the smallest cluster. In addition, all clusters scored at least 3 for Factor IV (verbal communication). Therefore, this study infers that the major Chinese inbound tourists to Taiwan in this study believe the differences between Taiwan and China are only minor. Some scholars have claimed that cultural similarity influences visitors' intention to travel a destination. For example, China is the popular destination for travelers from Hong Kong because of its similar cultural background. Hong Kong remains the most popular option among the three Chinese tourists [62]. Basala and Klenosky [63] also showed that people tend to visit a destination if they share a common language.

\subsection{Empirical Result of the Travel Demand}

This study uses the total number of Chinese inbound tourists to Taiwan to estimate the travel demand of traveling in Taiwan. The price, cross and income elasticity among cultural and cognitive clusters were estimated by combining travel cost with the ratio of travel cost per tourist/frequency of visits in each cluster. Table 4 shows that there are significant differences in price elasticity among four clusters of cultural and cognitive distance at a significant level of $1 \%(\mathrm{~F}$ value $=12.36)$. The "cultural similarity" cluster has the highest coefficient of price elasticity (0.35), followed by "interactive communication" (0.33), "integrative heterogeneity" (0.32), and "similar living habits" (0.26). Similarly, there are significant differences in cross elasticity among the four clusters at $1 \%$ ( $F$ value $=26.141)$. The "cultural similarity" cluster has the highest coefficient of cross elasticity (0.34), followed by "interactive communication" (0.33), "integrative heterogeneity" (0.25), and "similar living habits" (0.23). As such, there are significant differences in income elasticity among the four clusters at a significant level of $10 \%$ (F value $=2.553)$. The "integrative heterogeneity" cluster has the highest coefficient of income elasticity (0.43), followed by "similar living habits" (0.41), "cultural similarity" (0.39), and "interactive communication" (0.34) (Table 4).

Based on above elasticity estimation, this study adopts the consumer surplus (CS) as the evaluation model to measure the differences of the recreational benefits among four cultural and cognitive clusters of Chinese tourists. In Equation (1), $\mathrm{CS}_{i}$ is the recreational benefit which $i$ inbound tourist could bring to Taiwan (i.e., Consumer Surplus), $C$ is the travel cost of visiting Taiwan; $x$ is frequency of visits following with the index demand function; $\beta_{0}$ is constant in the $e^{\beta 0+\beta 1 C} ; \beta_{1}$ is the estimated coefficient of the travel cost; $C^{0}$ is the travel cost of current period. On the basis of the formula 2, the recreational benefit of inbound tourists could be assessed on the basis of the ratio of frequency of visits/travel cost per inbound tourist each year.

$$
\mathrm{CS}_{\mathrm{i}}=\int_{\mathrm{C}^{0}}^{\infty} e^{\beta 0+\beta 1 C} d c=\left[\frac{e^{\beta 0+\beta 1 C}}{\beta 1}\right] \quad \begin{aligned}
& C \rightarrow \infty \\
& C=C_{0}
\end{aligned}=\frac{\mathrm{X}_{i}}{\beta 1}
$$

The estimation results for the on-site Poisson travel demand model shows that the recreational benefit (CS) of the cultural distance clusters of the international Chinese tourists is US\$ 5736, which ranges from US\$ 4733 to US\$ 6740 at the confidential interval of 95\% (Table 5). Based on significant differences among four clusters of the cultural and cognitive distance, the estimation of the recreational benefit of "interactive communication" cluster is US $\$ 4092$, which ranges from US $\$ 3089$ to US $\$ 5096$ at the confidential interval of $95 \%$; the estimation of the recreational benefit of "integrative heterogeneity" cluster is US\$ 5594, which ranges from US\$ 4590 to US\$ 6597 at the confidential interval of 95\%; the estimation of the recreational benefit of "similar living habits" cluster is US\$ 7053, which ranges from US\$ 6049 to US\$ 8056 at the confidential interval of 95\%; the estimation of the recreational benefit of "cultural similarity" cluster is US\$ 5635 , which ranges from US\$ 4631 to US\$ 6638 at the confidential interval of $95 \%$. Among the above four clusters, the "similar living habits" cluster has the highest 
recreational benefit, followed by "cultural similarity," "integrative heterogeneity," and "interactive communication."

Table 4. Estimation of three elasticity of travel demand model.

\begin{tabular}{cccccc}
\hline & $\begin{array}{c}\text { Interactive } \\
\text { Communication }\end{array}$ & $\begin{array}{c}\text { Integrative } \\
\text { Heterogeneity }\end{array}$ & $\begin{array}{c}\text { Similar Living } \\
\text { Habits }\end{array}$ & $\begin{array}{c}\text { Cultural } \\
\text { Similarity }\end{array}$ & F-Value \\
\hline Price elasticity & -0.33 & -0.32 & -0.26 & -0.35 & $12.36^{* * *}$ \\
\hline Cross elasticity & 0.33 & 0.25 & 0.23 & 0.34 & $26.141^{* * *}$ \\
\hline $\begin{array}{c}\text { Income } \\
\text { elasticity }\end{array}$ & 0.34 & 0.43 & 0.41 & 0.39 & $2.553^{*}$ \\
\hline
\end{tabular}

$* * *$ at the significant level of $1 \% ;{ }^{*}$ at the significant level of $10 \%$.

Table 5. Estimation of the recreational benefit of the cultural distance among Chinese inbound tourists to Taiwan.

\begin{tabular}{cccccc}
\hline Cluster & $\begin{array}{c}\text { Interactive } \\
\text { Unit }\end{array}$ & $\begin{array}{c}\text { Integrative } \\
\text { Communication } \mathbf{( N = 1 4 4 )}\end{array}$ & $\begin{array}{c}\text { Similar Living } \\
\text { Habits (N = 214) }\end{array}$ & $\begin{array}{c}\text { Cultural Similarity } \\
\mathbf{( N = 2 6 2 )}\end{array}$ & $\begin{array}{c}\text { Consumer Surplus } \\
\mathbf{( N = 7 4 9 )}\end{array}$ \\
\hline Dollar/Year/Person & 4092 & 5594 & 7053 & 5635 & 5736 \\
\hline $\begin{array}{c}95 \% \mathrm{CI}^{*} \\
(\text { Dollar/Year/Person) }\end{array}$ & $(3089,5096)$ & $(4590,6597)$ & $(6049,8056)$ & $(4631,6638)$ & $(4733,6740)$ \\
\hline
\end{tabular}

Note: $\mathrm{CI}^{*}$ is confidential interval.

\section{Conclusions}

\subsection{Conclusions}

The results show that there are four derived factors through factor analysis including "social environment," "personal relationship," "living arrangements," and "verbal communication." The tourists who choose to travel to Taiwan enjoy similar local living environments as the Taiwanese. Thus, social environment is a key factor in the perceived cultural distance among Chinese tourists. Consistent with prior studies [31-34], Social and cultural distance could reduce the travel constraint (cultural and/or social customs, languages, eating habits, etc.). In other words, visiting the same cultural destination reduces the intensity of cultural shock, causing a positive experience [18]. There is a highly similar social environment between Taiwan and other Chinese countries, which greatly assists in developing cultural tourism in Taiwan. This study further used cluster analysis to divide subjects into four cultural cognitive clusters ("interactive communication," "integrative heterogeneity," "similar living habits," and "cultural similarity") for market segmentation and for exploring the feeling of traveling to Taiwan among clusters. The results reveal that the "cultural similarity" cluster was the majority group, and "integrative heterogeneity" was the minority group. The evaluation score of "interactive communication" among all four clusters was greater than 3, so most Chinese inbound tourists to Taiwan did not see much difference between Taiwan and China. In addition, this study included the cultural distance and tourist type in the travel demand model of Chinese inbound tourists, achieving the study goal of estimating the travel demands of tourists based on cultural distance. Consistent with past travel demand models $[45,46,64]$, the results prove that the outcome of the current On-Site Poisson travel demand model, and show the different recreations benefits among four clusters of perceived cultural distance The results show that the higher cost of traveling to Taiwan, the less frequency of visiting Taiwan; the higher the cost of traveling to a substitute country or the higher the tourists' incomes, the higher the frequency of visiting Taiwan. In addition, the longer the tourists stay in Taiwan, the higher the tourists' perceived value; the higher the tourists' perceived value and satisfaction, the higher the frequency of visiting Taiwan. 


\subsection{Management Implications}

This study identifies that most Chinese international tourists traveling in Taiwan rarely perceive the cultural differences between Taiwan and China. Among Chinese international tourists to Taiwan, "life arrangement cluster" has higher recreation travel demand and "interactive communication cluster" has lower demand than other groups. Thus, the Taiwan Tourism Bureau and Taiwanese travel industry should emphasize living environments, traditions, and conveniences that are similar to Great Chinese Regions. This can attract more Chinese tourists who have similar life arrangements and increase Chinese tourists' travel to Taiwan. The "similar living habits cluster" has the highest recreation benefit and "integrative heterogeneity cluster" has the lowest recreation benefit for the Taiwan travel industry. Thus, the government and travel industries should pay attention to "similar living habits cluster" in order to bring the maximum reaction benefit by delivering an appropriate quality of service to match visitors' needs and living habits, which, in turn, impacts their perceptions of value and influences loyalty so as to maintain tourist numbers. In addition, the Taiwan Tourism Bureau and Taiwanese travel industry should provide experiences for tourists aimed to elevate overall satisfaction, this could increase the frequency of tourists visiting Taiwan. Among Chinese inbound tourists to Taiwan, "life arrangement" has higher recreation travel demand and "interactive communication" has lower demand than other the three clusters. Thus, the Taiwan Tourism Bureau and Taiwanese travel industry should emphasize living environments, traditions, and conveniences that are similar to other Asian areas. This can attract more Chinese tourists who have similar life arrangements and increase Chinese tourists' travel to Taiwan. By solely depending on "verbal communication" in the Asian travel market, this study finds that Taiwan will neither attract more Chinese inbound tourists nor increase tourists' recreation demand. The primary contribution of this study is the establishment of a measurement scale for cultural and cognitive distance among Chinese inbound tourists to Taiwan, and the segmentation of the inbound tourism market based on cultural distance. The aforementioned results help to understand thoughts, perceptions, and cognitions from different kinds of Chinese inbound tourists to Taiwan. The findings could also assist the Taiwan Tourism Bureau and travel managers or promoters value these tourists' travel demands and cultural and cognitive distance in order to attract more kinds of tourists via applicable market segmentation in the Taiwan inbound tourist market. Thus, the travel and tourism industry or planners could develop effective marketing strategies (e.g., promoting cultural similarities between Taiwan and China when designing group package tours), market segmentation, and positioning for Chinese inbound tourists to Taiwan.

\subsection{Limitations and Further Research}

This study, under the time and resource limitations, employed a non-random sampling method (i.e., the purposive sampling method) in the data collection procedure, causing its results to have a limited generalization to various populations. Future researchers could adopt the random sampling method in collecting data to obtain better generalization of the results. Furthermore, the study, for the tourism market, develops a framework, using the Travel Cost Method to estimate tourists' travel demands and benefits. For the other markets, researchers could employ the other suitable evaluation methods (e.g., the Contingent Valuation Method) to estimate different customers' demands and benefits.

Author Contributions: Five co-authors had together contributed to the completion of this article. Formal analysis; investigation; data curation and writing-original draft preparation, C.-H.L.; validation, formal analysis, investigation, data curation, review and editing, H.-S.C.; writing-original draft preparation, writing-review and editing, G.-B.L. and B.-K.T.; and supervision, investigation, resources, C.-M.H.

Funding: This research received no external funding.

Conflicts of Interest: The authors declare no conflict of interest. 


\section{References}

1. World Travel \& Tourism Council. Travel \& Tourism Economic Impact 2017 World. 2017. Available online: https: / /www.wttc.org/-/media/files/reports/economic-impact-research/regions-2017/world2017.pdf (accessed on 7 October 2018).

2. World Travel and Tourism Council. World Travel \& Tourism Council Unveils 2018 Economic Impact Reseach Report. 2018. Available online: https://www.wttc.org/-/media/files/reports/economic-impact-research/ countries-2018/taiwan2018.pdf (accessed on 15 September 2018).

3. Taiwan Tourism Bureau Ministry. 2017 Annual Survey Report on Visitors Expenditure and Trends in Taiwan. 2018. Available online: http:/ / admin.taiwan.net.tw/indexc.asp (accessed on 1 February 2018).

4. Taiwan Tourism Bureau Ministry. 2017 Visitor Arrivals by Residence. 2018. Available online: https: / / admin.taiwan.net.tw/statistics / year.aspx?no=134 (accessed on 12 September 2018).

5. Linton, R. The Cultural Background of Personality; Appleton Century: New York, NY, USA, 1945.

6. Clark, T.; Pugh, D.S. Foreign country priorities in the internationalization process: A measure and an exploratory test on British firms. Int. Bus. Rev. 2001, 10, 285-303. [CrossRef]

7. Sousa, C.M.P.; Bradley, F. Cultural distance and psychic distance: Two peas in a pod? J. Int. Mark. 2006, 14, 49-70. [CrossRef]

8. Figueiredo, O.; da Rocha, A.; da Silva, J.F.; Carneiro, J. Mapping the conceptual domain of the psychic distance construct. In Proceedings of the 34th Annual EIBA Conference, Tallinn, Estonia, 11-13 December 2008.

9. Lim, C.; McAleer, M. Analyzing the behavioral trends in tourist arrivals from Japan to Australia. J. Travel Res. 2005, 43, 414-421. [CrossRef]

10. Mak, J.; Carlile, L.; Dai, S. Impact of population aging on Japanese international travel to 2025. J. Travel Res. 2005, 44, 151-162. [CrossRef]

11. Wang, Y.; Lim, C. Assessing forecasting models for outbound Japanese travellers to Australia and China. J. Appl. Econ. Manag. 2005, 3, 1-15.

12. Dybka, J. Overseas travel to Canada: New research on the perceptions and preferences of the pleasure travel market. J. Travel Res. 1988, 26, 12-15. [CrossRef]

13. Holzner, L. Stadland USA. Geogr. Z. 1985, 75, 192-205.

14. Ritter, W. Styles of tourism in the modern world. Tour. Recreat. Res. 1987, 12, 3-8. [CrossRef]

15. Pizam, A.; Jeong, G. Cross-cultural tourist behavior: Perceptions of Korean tour-guides. Tour. Manag. 1996, 17, 277-286. [CrossRef]

16. Pizam, A.; Sussman, S. Does nationality affect tourist behavior? Ann. Tour. Res. 1995, 22, 901-917. [CrossRef]

17. Sheldon, P.J.; Fox, M. The role of foodservice in vacation choice and experience: A cross-cultural analysis. J. Travel Res. 1988, 27, 9-16. [CrossRef]

18. Ng, S.I.; Lee, J.A.; Soutar, G.N. Tourists' intention to visit a country: The impact of cultural distance. Tour. Manag. 2007, 28, 1497-1506. [CrossRef]

19. Crotts, J.C. The effect of cultural distance on overseas travel behaviors. J. Travel Res. 2004, 43, 83-88. [CrossRef]

20. O'Leary, S.; Deegan, J. People, pace, place: Qualitative and quantitative images of Ireland as a tourism destination in France. J. Vacat. Mark. 2003, 9, 213-226. [CrossRef]

21. McKercher, B.; Cros, H.D. Testing a cultural tourism typology. Int. J. Tour. Res. 2003, 5, 45-58. [CrossRef]

22. Shenkar, O. Cultural distance revisited: Toward a more rigorous conceptualization and measurement of cultural differences. J. Int. Bus. Stud. 2001, 32, 519-536. [CrossRef]

23. Jackson, M. Cultural influences on tourist destination choices of 21pacific rim nations. In Proceedings of the CAUTHE National Research Conference, Canberra, Australia, 7-10 February 2001; pp. 166-176.

24. Hewison, R. The Heritage Industry: Britain in a Climate of Decline; Methuen: London, UK, 1987.

25. Hughes, H.L. Culture as a tourist resource: A theoretical consideration. Tour. Manag. 1987, 30, $205-216$. [CrossRef]

26. Prentice, R. Experiential cultural tourism: Museums and the marketing of the new romanticism of evoked authenticity. Mus. Manag. Curatorship 2001, 19, 5-26. [CrossRef]

27. Richards, G. Tourism attraction systems: Exploring cultural behavior. Ann. Tour. Res. 2002, 29, $1048-1064$. [CrossRef] 
28. Elena, G.P. Cultural Distance among Speakers of the Same Language. Available online: http://www.senspublic.org /article.php3?id_article=653\&lang=fr (accessed on 25 November 2013).

29. Hofstede, G. Cultural Consequnces, 2nd ed.; Sage: Thousand Oaks, CA, USA, 2001.

30. Ahn, M.J.; McKercher, B. The effect of cultural distance on tourism: A study of international visitors to Hong Kong. Asia Pac. J. Tour. Res. 2015, 20, 94-113. [CrossRef]

31. Joo, D.; Tasci, A.D.; Woosnam, K.M.; Maruyama, N.U.; Hollas, C.R.; Aleshinloye, K.D. Residents' attitude towards domestic tourists explained by contact, emotional solidarity and social distance. Tour. Manag. 2018, 64, 245-257. [CrossRef]

32. Tasci, A.D. Social distance: The missing link in the loop of movies, destination image, and tourist behavior? J. Travel Res. 2009, 47, 494-507. [CrossRef]

33. Yilmaz, S.S.; Tasci, A.D. Circumstantial impact of contact on social distance. J. Tour. Cult. Chang. 2015, 13, 115-131. [CrossRef]

34. Nyaupane, G.P.; Timothy, D.J.; Poudel, S. Understanding tourists in religious destinations: A social distance perspective. Tour. Manag. 2015, 48, 343-353. [CrossRef]

35. Woosnam, K.M.; Lee, Y.J. Applying social distance to voluntourism research. Ann. Tour. Res. 2011, 38, 309-313. [CrossRef]

36. McKercher, B.; Chow, B. Cultural distance and cultural tourism participation. Pac. Tour. Rev. 2001, 5, 21-30.

37. Kogut, B.; Singh, H. The effect of national culture on the choice of entry mode. J. Int. Bus. Stud. 1988, 19, 411-432. [CrossRef]

38. Hofstede, G. Culture's Consequences: International Differences in Work-Related Values; Sage: Beverly Hills, CA, USA, 1980. [CrossRef]

39. Ronen, S.; Shenkar, O. Clustering countries on attitudinal dimensions: A review and synthesis. Acad. Manag. Rev. 1985, 10, 435-454. [CrossRef]

40. West, J.; Graham, J.L. A linguistic-based measure of cultural distance and its relationship to managerial values. Manag. Int. Rev. 2004, 44, 239-260.

41. Spradley, J.P.; Philips, M. Culture and stress: A quantitative analysis. Am. Anthropol. 1972, 74, 518-529. [CrossRef]

42. Hotelling, H. Letter to the national parks service. Eco Stud. Outdoor Recreat. 1947, 56, 36-120.

43. Clawson, M.; Knetsch, J.L. Economics of Outdoor Recreation; Resources for the Future: Washington, DC, USA, 1966.

44. Yu, Y.J. Evaluation of Visitor Destination Image and Tourism Demand at the Culture Resort of the Jiang. Master's Thesis, National Dong Hwa University, Hualieng, Taiwan, 2009.

45. Lee, C.H. Evaluation of motivation styles and economic benefits in festival-A case of Yi-Lan Green Exposition. J. Agric. Econ. 2008, 83, 59-93.

46. Lee, C.H.; Huang-Chin, H. Measuring economic benefits from festival visitor's crowding perceived reduction. Taiwan. Agric. Econ. Rev. 2009, 15, 81-113.

47. Lee, C.H.; Chen, C.C. Evaluation of Visitor Travel Demand and Recreation Benefits in the Special Event-A Case of Yi-Lan Green Exposition. Agric. Econ. 2007, 39, 137-166.

48. Cho, S.Y. The Ugly Koreans are coming? Bus. Korea 1991, 9, 25-31.

49. Chen, C.C. Chinese Tourists' Needs, Attitudes, and Behavioral Intentions for Food and Beverages in Taiwan. Master's Thesis, National Kaohsiung University of Hospitality and Tourism, Kaohsiung, Taiwan, June 2010.

50. Sung, Y.F. Travel Motivation, Perceived Value, Satisfaction and Loyalty-Study Foreign Tourists Travel to Taiwan. Master's Thesis, Ming Chua University, Taipei, Taiwan, June 2010.

51. Chou, H. Exploring Hong Kong, Macau and Japan Inbound Tourists' Destination Images, Shopping Behaviors and Decision Rules. Master's Thesis, Feng Chia University, Taichung, Taiwan, June 2009.

52. Cheng, Y.P. The Study of Tourism Behavior, Satisfaction and Revisiting Willingness of Japanese Tourists to Taiwan. Master's Thesis, National Normal University, Taipei, Taiwan, June 2009.

53. Wu, H.-Y. A Study of the Taiwan Traveling Image from China Tourists. Master's Thesis, National Dong Hwa University, Hualieng, Taiwan, June 2008.

54. Yang, M.-H. The Study of Impact of Socio-Demographics and Travel Characteristics of Tourists from Mainland China on Their Travel Satisfaction. Master's Thesis, National Normal University, Taipei, Taiwan, June 2008.

55. Selmer, J.; Chiu, R.K.; Shenkar, O. Cultural distance asymmetry in expatriate adjustment. Cross Cult. Manag. Int. J. 2007, 14, 150-160. [CrossRef] 
56. Kaiser, H.F. An index of factorial simplicity. Psychometrika 1974, 39, 31-36. [CrossRef]

57. Comrey, A.; Lee, H. A First Course in Factor Analysis; Erlbaum: Hillsdale, NJ, USA, 1992.

58. Byrne, D.; Nelson, D. Attraction as a linear function of proportion of positive reinforcements. J. Pers. Soc. Psychol. 1965, 1, 659-663. [CrossRef] [PubMed]

59. Wang, C.K.; Lamb, C.W. The impact of selected environmental forces upon consumers' willingness to buy foreign products. J. Acad. Mark. Sci. 1983, 11, 71-84. [CrossRef]

60. Watson, J.J.; Wright, K. Consumer ethnocentrism and attitudes toward domestic and foreign products. Eur. J. Mark. 2000, 34, 1149-1166. [CrossRef]

61. Hair, J.F.; Black, W.C.; Babin, B.J.; Anderson, R.E. Multivariate Data Analysis, 7th ed.; Prentice Hall: Englewood Cliffs, NJ, USA, 2010.

62. Travel China Guide. Tourism. China Inbound Tourism in 2017. 2017. Available online: https://www. travelchinaguide.com/tourism/2017statistics/inbound.htm (accessed on 4 November 2018).

63. Basala, L.S.; Klenosky, D.B. Travel style preferences for visiting a novel destination: A conjoint investigation across the novelty familiarity continuum. J. Travel Res. 2001, 40, 172-182. [CrossRef]

64. Prayaga, P.; Rolfe, J.; Sinden, J. A travel cost analysis of the value of special events: Gemfest in Central Queensland. Tour. Econ. 2006, 12, 403-420. [CrossRef]

(C) 2018 by the authors. Licensee MDPI, Basel, Switzerland. This article is an open access article distributed under the terms and conditions of the Creative Commons Attribution (CC BY) license (http:/ / creativecommons.org/licenses/by/4.0/). 